ఠ ORIGINAL RESEARCH

\title{
miR-2I inhibits the effects of cyclooxygenase-2 inhibitor NS398 on apoptosis and invasion in gastric cancer cells
}

This article was published in the following Dove Press journal:

OncoTargets and Therapy

4 November 2015

Number of times this article has been viewed

\author{
Huanqing $\mathrm{Li}^{\prime}$ \\ Jian Cheng ${ }^{2}$ \\ Yuqing Mao' \\ Miao Jiang' \\ Xiaoming Fan $^{1,2}$ \\ 'Department of Gastroenterology, \\ Jinshan Hospital, ${ }^{2}$ Department of \\ Internal Medicine, Shanghai Medical \\ College, Fudan University, Shanghai, \\ People's Republic of China
}

Correspondence: Xiaoming Fan Department of Gastroenterology, Jinshan Hospital, Fudan University, 1508 LongHang Road, JinShan District, Shanghai 20I508, People's Republic of China

Tel +862134189990 ext 5389

$\mathrm{Fax}+862167226910$

Email xiaomingfan57@sina.com
Objective: To investigate the role of miR-21 in cyclooxygenase-2 inhibitor NS398-induced apoptosis and invasion in gastric cancer (GC) cells.

Methods: AGS cells were treated with NS398 and transfected with miR-21. Quantitative realtime polymerase chain reaction was used to measure miR-21 mRNA expression. Apoptotic cells were assessed by terminal deoxynucleotidyl transferase-mediated dUTP nick end-labeling and flow cytometric analysis. The protein expression of cleaved caspase-3, Bcl-2, Bax, Bak, and PTEN was detected by Western blot. The capacities for invasion and migration were measured by transwell and wound-healing assays, respectively.

Results: Treatment of AGS cells with NS398 induced apoptosis in a dose-dependent manner accompanied by significant downregulation of miR-21 mRNA expression. Upregulation of miR-21 expression by transfection of miR-21 mimics into AGS cells blocked NS398-induced apoptosis. Treatment of AGS cells with NS398 induced changes in Bcl-2 protein family members, showing an increase in the protein expression of Bax, Bak, and PTEN, with a concomitant decrease in the protein expression of Bcl-2. In cells transfected with miR-21 mimics, these changes were reversed. The decrease in cellular invasiveness and migration induced by NS398 was blocked by upregulation of miR-21.

Conclusion: miR-21 mediates anticancer effects of NS398 in GC cells by regulating apoptosisrelated proteins. miR-21 is one of the molecular targets of this specific cyclooxygenase- 2 inhibitor in the prevention and treatment of GC.

Keywords: gastric cancer cells, apoptosis, stomach neoplasms, cyclooxygenase 2 inhibitors

\section{Introduction}

Gastric cancer (GC) is a major health care problem from a global perspective, with 989,000 new GC cases arising annually worldwide. ${ }^{1}$ Despite great advances in the diagnosis and treatment of GC, approximately 700,000 people die from GC worldwide each year. ${ }^{2}$ Gastric carcinogenesis represents a stepwise progression from chronic inflammation to invasive adenocarcinomas and distant metastasis. Epidemiological evidence indicates that environmental factors play a major role in carcinogenesis. In addition to environmental factors, GC is a complex, multistep process involving deregulation of canonical oncogenic pathways, including the cyclooxygenase-2 (COX-2)/prostaglandin E2 pathway. ${ }^{3}$

The COX protein is a key enzyme that catalyzes the formation of prostaglandins and other eicosanoids from arachidonic acid. Two isoforms of COX have been identified: COX-1 and COX-2;,5 COX-1 is considered to be a housekeeping gene and is thought to be related to the cytoprotection of gastric mucosa, while $C O X-2$ is an inducible intermediate-early gene, and its roles have been connected to inflammation and carcinogenesis. ${ }^{6}$ 
The expression of COX-2 and prostaglandins has not only been associated with various types of cancer but also been shown to be directly proportional to their aggressiveness. Evidence shows that increased expression of COX-2 is linked to GC development and progression. ${ }^{7}$ Thus, inhibition of COX-2 activity has become one of the preferred targets for cancer reduction. ${ }^{8}$ Specific COX-2 inhibitors such as NS398 have been investigated as chemopreventive and potentially chemotherapeutic agents. ${ }^{9-11}$ Recent studies have also shown that the COX-2 inhibitor celecoxib has a preventive effect against Helicobacter pylori-associated GC. ${ }^{12,13}$ However, the molecular mechanisms underlying the chemopreventive and chemotherapeutic effects of COX-2 inhibitors remain unclear. In addition to $\mathrm{COX}$-dependent mechanisms, COX-2 inhibitors are known to mediate their effect by COX-independent mechanisms. ${ }^{14}$

MicroRNAs (miRNAs) are a newly discovered class of posttranscriptional regulators. They are small noncoding RNAs that are 18-25 nucleotides in length. To date, more than 900 miRNAs have been identified in humans. This class of molecule has the capacity to specifically inhibit translation or induce mRNA degradation, by predominantly targeting the 3 ' untranslated regions of mRNA. ${ }^{15}$ miRNAs are differentially expressed in various diseases, thus implicating them in normal and pathological molecular mechanisms, ${ }^{16}$ and they have been shown to be involved in the pathogenesis of many types of cancer, including GC. ${ }^{17}$ Genes coding for these miRNAs have been characterized as novel proto-oncogenes and tumorsuppressor genes based on findings that they control malignant phenotypes such as proliferation, resistance to apoptosis and invasiveness. ${ }^{18}$ Among these miRNAs, miR-21 has been demonstrated to influence proliferation, invasion, metastasis, and chemoresistance in different cancer cell lines. ${ }^{19-22} \mathrm{miR}-21$ is one of the most commonly and highly upregulated miRNAs in GC. ${ }^{19-22}$ The expression of miR-21 is significantly increased in GC cases with larger tumor sizes, poor differentiation, metastasis with lymph node involvement, and later stage disease. ${ }^{22}$ Overexpression of miR-21 significantly enhances cell proliferation and invasion in GC cells, suggesting that it plays a pivotal role in GC pathogenesis and progression. ${ }^{23}$

In this study, we investigated the role of miR-21 in NS398induced changes of apoptosis, invasiveness, and migration in AGS GC cells and further explored the molecular mechanism. The results show that miR-21 expression is downregulated by treatment with the COX-2 inhibitor NS398, in parallel with GC cell apoptosis. Forced expression of miR-21 reversed changes in apoptosis and invasiveness induced by NS398 in GC cells. miR-21 mediated the changes in the protein expression of
Bcl-2, Bax, and Bak induced by NS398. Our results suggest that miR-21 is one of the molecular targets of this specific COX-2 inhibitor in the prevention and treatment of GC.

\section{Methods}

This study had ethics approval from the ethics committee of Fudan University, Shanghai, People's Republic of China.

\section{Materials}

Antibodies against Bcl-2, PTEN, Bak, and Bax were purchased from Santa Cruz Biotechnology Inc. (Dallas, TX, USA). Bicinchoninic acid was purchased from Pierce Chemicals (Rockford, IL, USA). An antibody against cleaved caspase-3 was obtained from Pharmingen (San Diego, CA, USA). The enhanced chemiluminescence system was obtained from Amersham (Arlington Heights, IL, USA). Proteinase inhibitors were obtained from Roche Molecular Biochemicals (Mannheim, Germany). Unless stated above, other materials were purchased from Sigma-Aldrich Co. (St Louis, MO, USA).

\section{Cell culture and treatment}

The AGS gastric adenocarcinoma cell line was purchased from the American Type Culture Collection (CRL-1739, Rockville, MD, USA). The cells were cultured in Roswell Park Memorial Institute (RPMI)-1640 medium (11875; Thermo Fisher Scientific, Waltham, MA, USA) supplemented with 10\% fetal bovine serum (10099-141, Thermo Fisher Scientific) and a 1\% antibiotic-antimycotic solution at $37^{\circ} \mathrm{C}$ in a humidified $5 \% \mathrm{CO}_{2}$ incubator. Cells were passaged every 5 days by washing twice in $5 \mathrm{~mL}$ phosphate-buffered saline (PBS), then incubating with $0.25 \%$ trypsin. The COX-2 inhibitor NS398 (Cayman Chemical Company, Ann Arbor, MI, USA) dissolved in RPMI-1640 medium (0, 50, and $100 \mu \mathrm{M} / \mathrm{L}$ ) was added to AGS cells inoculated into a six-well plate. NS398 was dissolved in dimethyl sulfoxide, and the control group was treated with dimethyl sulfoxide alone at a final concentration of $0.1 \%$.

The study comprised five experimental groups: NS398 group (50 and $100 \mu \mathrm{M} / \mathrm{L}), \mathrm{NS} 398(100 \mu \mathrm{M} / \mathrm{L})+$ miRNA-NC (negative control), NS398 $(100 \mu \mathrm{M} / \mathrm{L})+$ miR-21 mimics, and normal control. In the NS398 $(100 \mu \mathrm{M} / \mathrm{L})+$ miRNA-NC (negative control) and NS398 $(100 \mu \mathrm{M} / \mathrm{L})+$ miR-21 mimics groups, NS398 was added 24 hours after transfection of miR-21 mimics or miRNA-NC.

\section{Cell transfection}

miR-21 mimics were transfected into AGS cells using Lipofectamine ${ }^{\circledR} 2000$ (Thermo Fisher Scientific, Waltham, 
MA, USA). Cells with mutant mimics and miRNA-NC without addition of NS398 were used as the randomized and blank control groups respectively. To perform the transfection, $100 \mathrm{pmol}$ of the mimics were diluted in $250 \mu \mathrm{L}$ of serum-free RPMI-1640 medium, and then $5 \mu \mathrm{L}$ of Lipofectamine ${ }^{\circledR} 2000$ were diluted in another $250 \mu \mathrm{L}$ serum-free RPMI-1640 medium. After incubating at room temperature for 5 minutes, the two agents were mixed gently and incubated at room temperature for 20 minutes. The resulting complexes were added to the cells and incubated overnight at $37^{\circ} \mathrm{C}$ in an atmosphere of $5 \% \mathrm{CO}_{2}$. In subsequent experiments, the medium was replaced with the same medium containing $10 \%$ fetal bovine serum. Total RNAs and proteins were extracted for analysis 24 hours after transfection.

\section{Quantitative real-time polymerase chain reaction}

Total RNA was extracted using TRIzol reagent (Thermo Fisher Scientific) for miR-21 mRNA analyses. For the detection of miR-21 expression, stem-loop quantitative real-time polymerase chain reaction (qRT-PCR) was performed using SYBR Premix Ex Taq ${ }^{\mathrm{TM}}$ (TaKaRa, Shiga, Japan) according to the manufacturer's protocol. Based on the sequence of miR-21, a stem-loop RT primer was designed with the following sequence: 5'-GTCGTATCCAGTGCAGGGTCC GAGGTATTCGCACTGGATACGACTCAACA-3'. One microgram of total RNA was reverse transcribed by under the following reaction conditions: $16^{\circ} \mathrm{C}$ for 30 minutes, $30^{\circ} \mathrm{C}$ for 5 minutes, $42^{\circ} \mathrm{C}$ for 30 minutes, $85^{\circ} \mathrm{C}$ for 5 minutes. The primer for U6 was: 5'-CTCGCTTCGGCAGCACA-3' (forward); 5'-AACGCTTCACGAATTTGCGT-3' (reverse). The qRT-PCR conditions were: $94^{\circ} \mathrm{C}$ for 30 seconds, $94^{\circ} \mathrm{C}$ for 10 seconds, $60^{\circ} \mathrm{C}$ for 30 seconds, for 40 amplification cycles. All qRT-PCR experiments were performed in triplicate and the experiments were repeated three times. Quantification of expression of each target was compared with untreated controls using the $2^{-\Delta \Delta \mathrm{Ct}}$ method. U6 was used as a control.

\section{Western blot analysis}

Proteins were analyzed by Western blot as previously described. ${ }^{24}$ AGS cells were plated at a density of $1 \times 10^{5}$ cells/ well in six-well plates. At 24 hours after treatment, the cells were washed with ice-cold PBS and lysed with lysis buffer. The cell lysate ( $50 \mu \mathrm{g}$ protein) was subjected to $10 \%$ sodium dodecyl sulfate-polyacrylamide gel electrophoresis, and the protein bands were transferred to a polyvinylidene difluoride membrane. The membrane was blocked with Tris-buffered saline containing $0.1 \%$ Tween 20 and $5 \%$ nonfat, dry milk for 1 hour, and then incubated overnight at $4{ }^{\circ} \mathrm{C}$ with the primary antibody $(1: 1,000)$. The membrane was washed three times with PBS containing $0.1 \%$ Tween 20 , and incubated with horseradish peroxidase-conjugated anti-rabbit immunoglobulin $\mathrm{G}$ as the secondary antibody $(1: 7,000)$ for 1 hour at room temperature. Protein bands were detected using the enhanced chemiluminescence system and analyzed using densitometry. Quantitative analysis was performed with beta-actin as an internal control.

\section{Flow cytometry}

Apoptotic cells were assessed using Annexin V staining, which was performed according to the protocol provided by the manufacturer. The cells were treated with different treatments for 48 hours, at the end of which a total of $10^{5}$ cells was harvested by trypsinization and washed twice in ice-cold PBS. The cells were then suspended in $400 \mu \mathrm{L}$ Annexin V-fluorescein isothiocyanate (FITC) binding buffer containing $5 \mu \mathrm{L}$ Annexin V-FITC and incubated at $37^{\circ} \mathrm{C}$ for 10 minutes. After this, the cells were resuspended in $190 \mu \mathrm{L}$ Annexin V-FITC binding buffer with $10 \mu \mathrm{L}$ propidium iodide. The apoptotic cells were analyzed by flow cytometry within an hour.

\section{TUNEL assay}

DNA breaks occur later in the apoptotic pathway and can be determined and analyzed by performing the terminal deoxynucleotidyl transferase-mediated dUTP nick endlabeling (TUNEL) assay (Kaiji Biotech, Nanjing, People's Republic of China). First, a total of $10^{5}$ cells were seeded onto coverslips after transfection with miR-21 mimics and treated with $100 \mu \mathrm{M} / \mathrm{L}$ NS398. For analysis, the cells were washed, fixed, and stained as per the manufacturer's instructions and apoptotic numbers evaluated using a confocal laser scanning microscope at $515-565 \mathrm{~nm}$.

\section{Transwell assay}

The transwell assay was performed as previously described..$^{25}$ In brief, $100 \mu \mathrm{L}$ of diluted matrigel (BD, Franklin Lakes, NJ, USA) was added to the upper chamber of wells of a 24-well transwell plate (Corning Incorporated, Corning, NY, USA). After the matrigel polymerized, $100 \mu \mathrm{L}$ of cell suspension $\left(1 \times 10^{5}\right.$ cells $\left./ \mathrm{mL}\right)$ was plated into the upper chamber, and $500 \mu \mathrm{L}$ of RPMI- 1640 medium containing $10 \%$ serum was added to the lower chamber. The cells were incubated for 24 hours. At the end of the incubation period, cells that could not migrate or invade through the pores were removed using a cotton swab. Filters were fixed with $90 \%$ ethanol, stained with $0.1 \%$ crystal violet (Beyotime Institute of 
Biotechnology, Jiangsu, People's Republic of China), and photographed. Cells adhering to the lower chamber surface were quantified by visualizing five random fields at a magnification of $\times 200$ and averaging as described.

\section{Wound-healing assay}

AGS cells were seeded into six-well plates $\left(1 \times 10^{5}\right.$ cells/well $)$ and allowed to grow to confluence. Confluent monolayers were scratched with a pipette tip. Plates were washed three times with PBS to remove nonadherent cells and serum-free RPMI1640 medium was added. The six-well plates were then incubated at $37^{\circ} \mathrm{C}, 5 \% \mathrm{CO}_{2}$ for 24 hours, and then photographed.

\section{Statistical analysis}

All data were analyzed using SPSS 11.5 software (SPSS Inc., Chicago, IL, USA). The results are expressed as mean \pm SEM. Analysis of variance, followed by Bonferroni's $t$-test, was used to evaluate differences among groups. $P<0.05$ was considered significant.

\section{Results}

NS398 induced apoptosis and decreased invasiveness accompanied by downregulation of miR-2I expression in AGS cells

To investigate the effects of NS398 in AGS cells, we performed flow cytometry and TUNEL assay. Flow cytometry showed that the proportion of apoptotic cells in the control group, the $50 \mu \mathrm{M} / \mathrm{L}$ group, and the $100 \mu \mathrm{M} / \mathrm{L}$ group was $2.98 \% \pm 0.2 \%$, $5.15 \% \pm 0.1 \%$, and $10.6 \% \pm 0.2 \%$, respectively. The rates of apoptosis in the treatment groups were significantly higher than in the control group $(P<0.05)$ (Figure 1A).

In the TUNEL assay, apoptosis-negative nuclei were stained blue. The cells positive for apoptosis presented with bigger nuclei that were brown in color. The apoptotic rates of the control group, the $50 \mu \mathrm{M} / \mathrm{L}$ group, and the $100 \mu \mathrm{M} / \mathrm{L}$ group were $2.06 \% \pm 0.3 \%, 9.36 \% \pm 1.5 \%$, and $14.39 \% \pm 1.7 \%$, respectively. The rates of apoptosis in the treatment groups were significantly higher than in the control group $(P<0.05)$ (Figure 1B). Treatment of AGS cells with NS398 induced apoptosis in a dose-dependent manner.

Next, we further assessed the effects of NS398 on cell migration, a key determinant of malignant progression and metastasis. We found that NS398 could significantly reduce the migratory abilities of AGS cells in the scratch woundhealing motility assay (Figure $1 \mathrm{C}$ ). In addition, the invasive capacity of AGS cells was reduced by $66.3 \%$ compared to the control group, with a mean of 41 cells versus 122 cells per six random microscopic fields $(P<0.05)$ (Figure 1D).

Finally, we tested whether NS398 affected the expression of miR-21 in AGS cells. In our study, the relative expression level of miR-21 was determined by qRT-PCR after the AGS cells were exposed to different concentrations of NS398. Treatment of AGS cells with NS398 significantly downregulated miR-21 expression (Figure 1E). These results suggested that miR-21 might be involved in NS398-induced anticancer effects in AGS cells.

\section{miR-2I reversed the changes of apoptosis, migratory, and invasive abilities induced by NS398 in AGS cells}

In order to confirm the role of miR-21 in NS398-induced apoptosis and inhibition of the invasiveness and migration in AGS cells, we investigated the effect of miR-21 overexpression on NS398-induced anticancer effects. The results showed that the expression of miR-21 was significantly increased after transfection of miR-21 mimics into AGS cells (Figure 2A).

Flow cytometric assay showed that the apoptotic rates of the NS398 $(100 \mu \mathrm{M} / \mathrm{L})$ group, NS398 $(100 \mu \mathrm{M} / \mathrm{L})+$ miRNA-NC group, NS398 $(100 \mu \mathrm{M} / \mathrm{L})+$ miR-21 mimics group were $10.33 \% \pm 0.1 \%, 11.17 \% \pm 0.1 \%$, and $6.49 \% \pm 0.2 \%$, respectively. The rates of apoptosis in the miR-21 mimic groups were significantly lower than in the control group $(P<0.05)$ (Figure 2B).

The TUNEL assay showed that the apoptotic rates of the miR-21 NC group and the miR-21 mimic group were $12.19 \% \pm 0.2 \%$ and $14.28 \% \pm 0.8 \%$, respectively. The rate of apoptosis in the miR-21 mimic group was significantly lower than in the control group $(P<0.05)$ (Figure $2 \mathrm{C}$ ).

In addition, we further assessed the effects of miR-21 mimics on cell migration, a key determinant of malignant progression and metastasis. We found that miR-21 mimics could significantly increase the migratory abilities of AGS cells in the scratch wound-healing motility assay (Figure 2D). The invasive capacity of AGS cells in the miR-21 mimics group was increased by $82 \%$ compared to the miR-21 NC group, with a mean of 86 cells versus 47 cells per six random microscopic fields $(P<0.05)$ (Figure $2 \mathrm{E})$. These results suggest that miR-21 mediates the anticancer effects of NS398.

\section{miR-2 I mediates anticancer effects of NS398 by regulating the protein expression ratio of $\mathrm{Bcl}-2 / \mathrm{Bax}$ and PTEN}

In order to further explore the molecular mechanisms of action of miR-21 on NS398-induced anticancer effects, we 


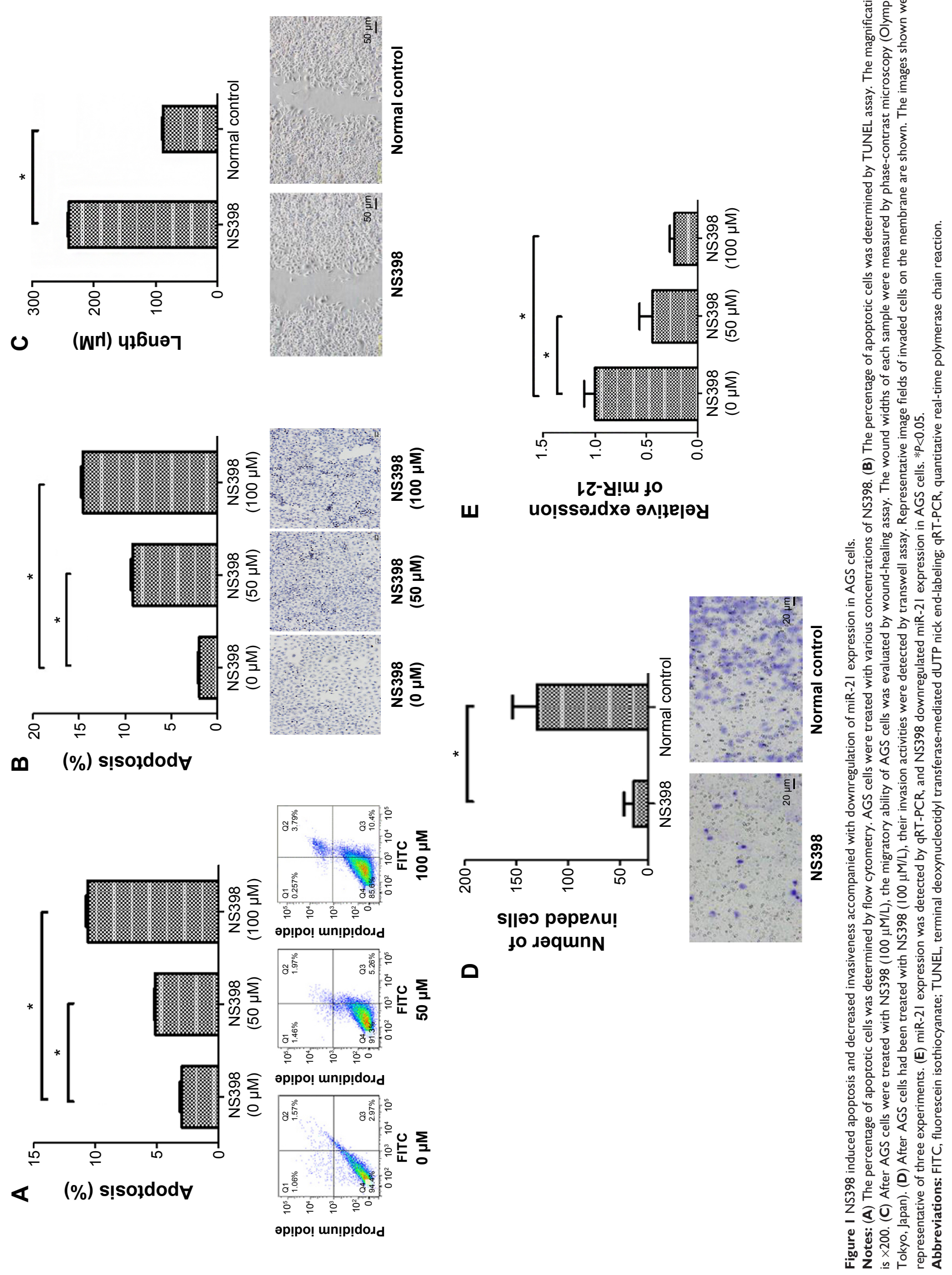



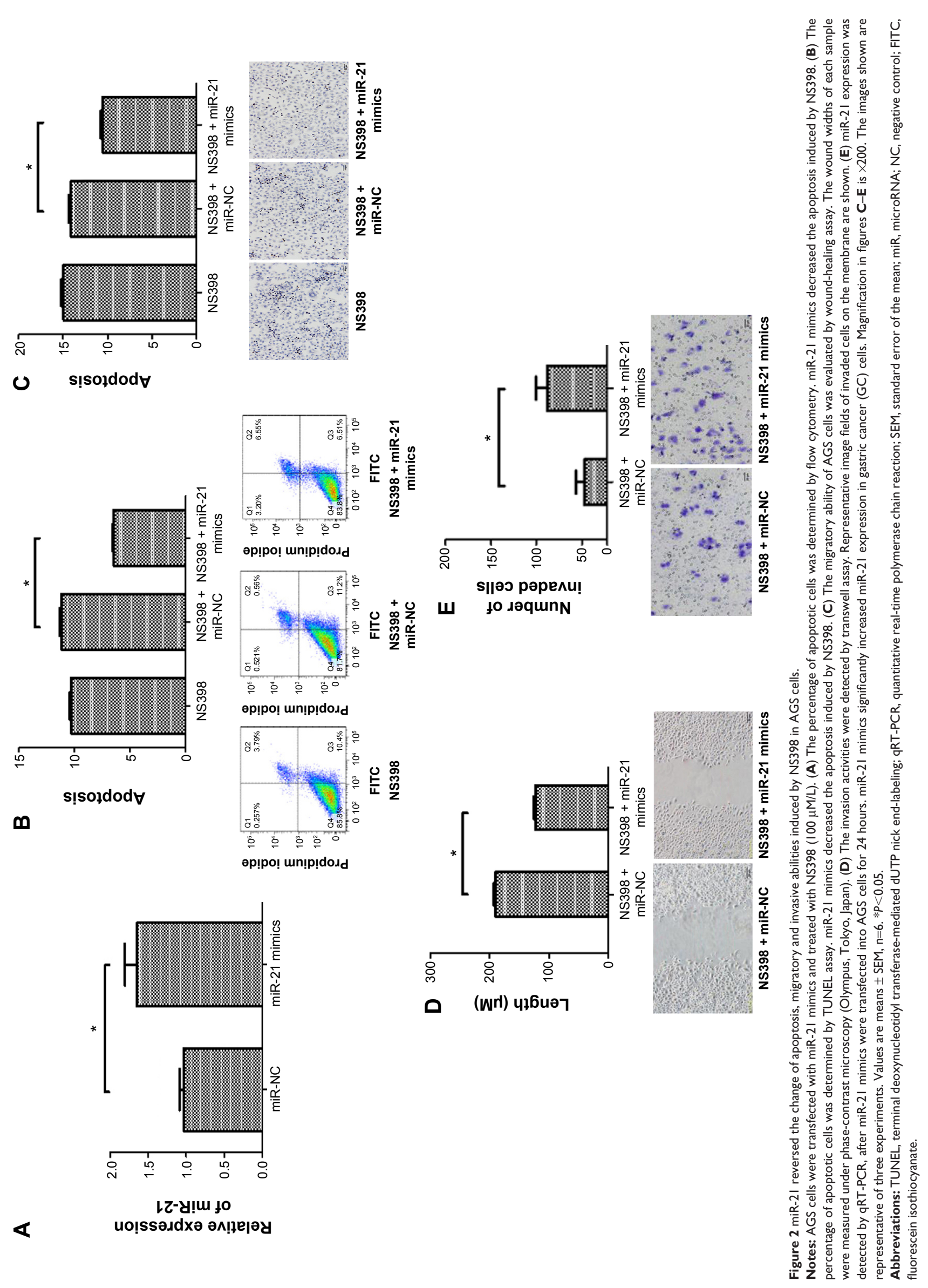


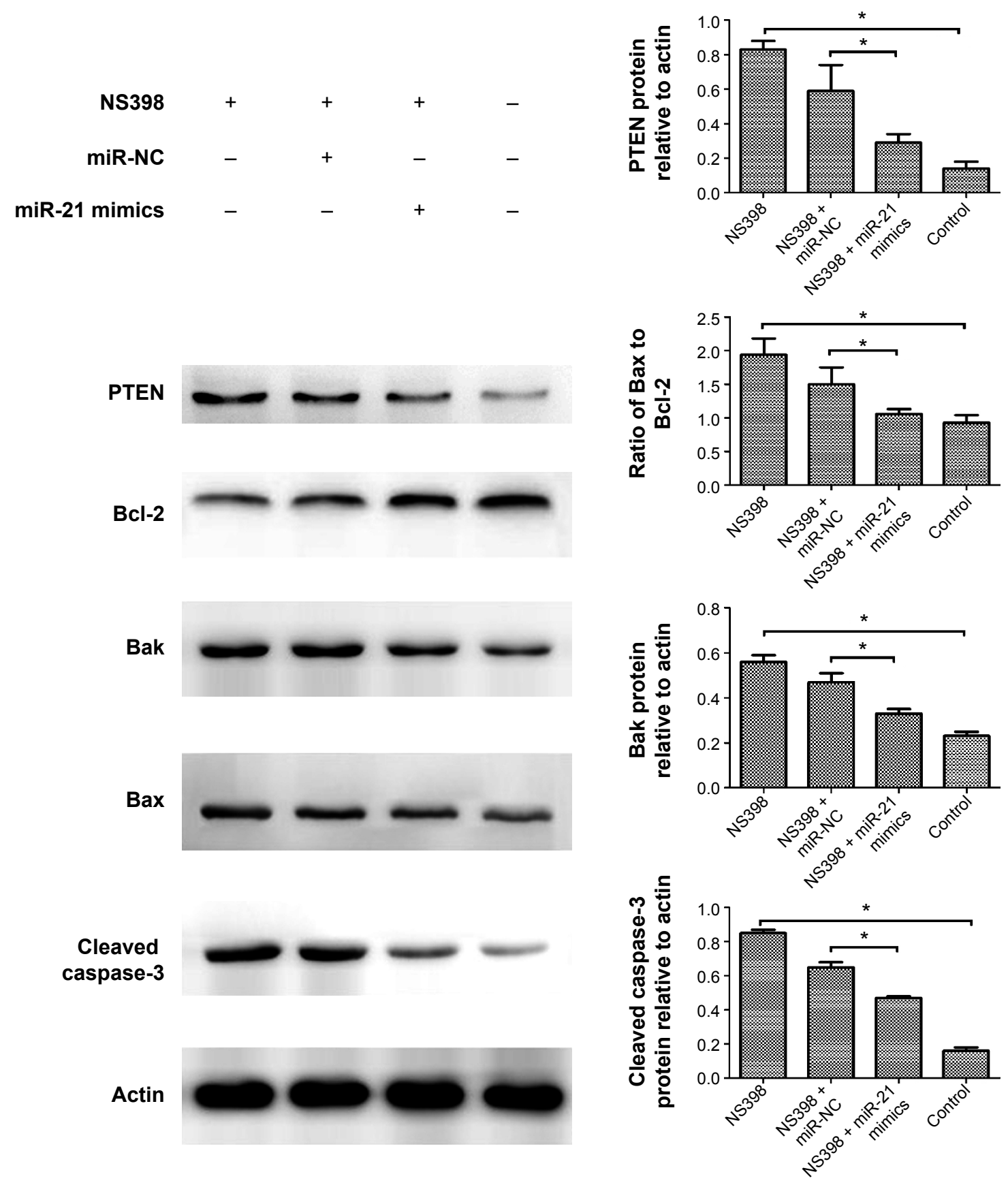

Figure 3 miR-2I mediates the anticancer effects of NS398 by regulating the protein expression ratio of Bcl-2/Bax and PTEN.

Notes: After AGS cells were transfected with miR-2I mimics and treated with NS398 (I00 $\mu \mathrm{M} / \mathrm{L})$ the expression levels of Bcl-2, Bak, Bax, cleaved caspase-3, and PTEN were measured by Western blot. Quantitative analysis was performed with beta-actin as the internal control $(* P<0.05)$.

Abbreviations: miR, microRNA; NC, negative control.

investigated the role of miR-21 in NS398-induced changes in the protein expression of Bcl-2 family members, caspase-3, and PTEN. Treatment of AGS cells with NS398 resulted in a significant decrease in Bcl-2 protein expression and an increase in Bax and Bak protein expression. In addition, caspase-3, which is a downstream target of the Bcl-2 family, was activated by the treatment with NS398. Finally, the protein expression of PTEN was also increased. However, these changes induced by NS398 treatment were reversed with the overexpression of miR-21. The results indicate that miR-21 mediates the anticancer effects of NS398 by regulating the protein expression ratio of $\mathrm{Bcl}-2 / \mathrm{Bax}$ and PTEN (Figure 3).

\section{Discussion}

NS398, a specific COX-2 inhibitor, has chemopreventive effects in gastrointestinal cancers. ${ }^{9} 10$ Previous studies showed that NS398 could effectively inhibit proliferation 
and induce apoptosis of human GC cells. ${ }^{26}$ miR-21 has been shown to be implicated in multiple malignancy-related processes including cell proliferation, apoptosis, invasion, and metastasis. ${ }^{27,28}$ High expression of miR-21 increases tumor cell proliferation, invasion, viability, and migration in lung squamous cell carcinoma. ${ }^{29}$ miR-21 was first implicated as an antiapoptotic factor by the observation that knockdown of miR-21 increased apoptotic cell death in human glioblastoma cells. ${ }^{30}$ However, the role of miR-21 in anticancer effects induced by specific COX-2 inhibitors has not been investigated in GC. In the present study, we used a specific COX-2 inhibitor, NS398, and showed that the expression level of miR-21 in AGS cells was reduced after NS398 treatment. We evaluated the apoptosis, migration, and invasion of AGS cells with miR-21 overexpression or NS398 treatment, and showed that increased miR-21 expression could reduce NS398-induced anticancer effects in AGS cells. The results showed that miR-21 could mediate the anticancer effects of NS398.

A study has affirmed that miR-21 inhibits the apoptosis of GC cell lines. ${ }^{31}$ However, the mechanisms of miR21-mediated NS398-induced cell apoptosis are not yet fully understood. Bcl-2 protein family members including Bcl-2, Bax, and Bak should be attractive biomarkers of apoptosis. Previous studies have shown that treatment with NS398 changes the expression of proapoptotic Bax and antiapoptotic $\mathrm{Bcl}-2$ involved in the mitochondrial pathway of apoptosis in GC cells. ${ }^{26,32}$ Shi et al showed that miR-21 overexpression appeared to downregulate Bax expression, and upregulate $\mathrm{Bcl}-2$ expression. ${ }^{33}$ Our studies examined the expression of Bax and Bcl-2 proteins in AGS cells following treatment with NS398 and miR-21 overexpression. Our results show that the treatment of cells with NS398 decreases the upregulation of Bax and Bak expression and increases the downregulation of Bcl-2 expression. Cells transfected with miR-21 mimics reverse these changes. These findings suggest a markedly inhibitory effect of miR-21 overexpression on NS398-mediated regulation in Bax/Bcl-2 ratios.

Caspase proteins are cysteine proteases that act downstream of the Bcl-2 family by initiating cellular breakdown during apoptosis. The caspases, especially caspase-3, are known to act downstream of $\mathrm{Bax} / \mathrm{Bcl}-2$ and play a key role in the execution of apoptosis. ${ }^{34}$ Among the effector caspases, caspase-3 is most frequently involved in neuronal apoptosis. Our results show that the treatment of cells with NS398 appears to increase caspase- 3 activity compared to the control group. However, this effect of caspase- 3 activity induced by NS398 treatment is prevented by miR-21 overexpression.
These results indicate that miR-21 overexpression can inhibit apoptosis induced by NS398 through regulating caspase-3 activity.

$P T E N$ is an important tumor suppressor gene and the functional inactivation of $P T E N$ by regulation of its expression is relevant to many solid tumors. PTEN is involved in GC pathology and its downregulation can lead to resistance to chemotherapeutic drugs including cisplatin in GC patients. ${ }^{35}$ Loss of functional PTEN leads to increased activity of AKT and mammalian target of rapamycin kinase pathways, which can promote both cell survival and proliferation through phosphorylation and inactivation of several downstream mediators. ${ }^{36}$ PTEN is a well-established downstream target of miR-21. ${ }^{37}$ More importantly, we demonstrate that the effect of cellular migration, invasion, and PTEN levels inhibited by NS398 treatment is partly prevented by miR-21 overexpression. These results indicate that miR-21 mediates cellular migration and invasion induced by NS398 through regulating the protein expression of PTEN.

\section{Conclusion}

This study demonstrates that miR-21 mediates anticancer effects of NS398 in GC cells by regulating apoptosis-related proteins. miR-21 is one of the molecular targets of a specific COX-2 inhibitor in the prevention and treatment of GC.

\section{Acknowledgments}

This study was supported by Key Clinical Discipline Construction of Shanghai Municipality (grant number K2012B20) and the Health Bureau of Jinshan District (grant number JSKJ-KTQN-201203).

\section{Disclosure}

The authors report no conflicts of interest in this work.

\section{References}

1. Ferlay J, Shin HR, Bray F, Forman D, Mathers C, Parkin DM. Estimates of worldwide burden of cancer in 2008: GLOBOCAN 2008. Int J Cancer. 2010;127:2893-2917.

2. Jemal A, Bray F, Center MM, Ferlay J, Ward E, Forman D. Global cancer statistics. CA Cancer J Clin. 2011;61:69-90.

3. Shi J, Qu YP, Hou P. Pathogenetic mechanisms in gastric cancer. World J Gastroenterol. 2014;20(38):13804-13819.

4. Parente L, Perretti M. Advances in the pathophysiology of constitutive and inducible cyclooxygenases: two enzymes in the spotlight. Biochem Pharmacol. 2003;65(2):153-159.

5. Vane JR, Bakhle YS, Botting RM. Cyclooxygenases 1 and 2. Annu Rev Pharmacol Toxicol. 1998;38:97-120.

6. Crofford LJ. COX-1 and COX-2 tissue expression: implications and predictions. J Rheumatol Suppl. 1997;49:15-19.

7. Cheng J, Fan XM. Role of cyclooxygenase-2 in gastric cancer development and progression. World J Gastroenterol. 2013;19(42):7361-7368. 
8. Misra S, Sharma K. COX-2 signaling and cancer: new players in old arena. Curr Drug Targets. 2014;15(3):347-359.

9. Howe LR, Dannenberg AJ. A role for cyclooxygenase- 2 inhibitors in the prevention and treatment of cancer. Semin Oncol. 2002;29:111-119.

10. Cao Y, Prescott SM. Many actions of cyclooxygenase-2 in cellular dynamics and in cancer. J Cell Physiol. 2002;190(3):279-286.

11. Sawaoka H, Kawano S, Tsuji S, et al. Cyclooxygenase-2 inhibitors suppress the growth of gastric cancer xenografts via induction of apoptosis in nude mice. Am J Physiol. 1998;274(1):1061-1067.

12. Kuo CH, Hu HM, Tsai PY, et al. Short-term celecoxib intervention is a safe and effective chemopreventive for gastric carcinogenesis based on a Mongolian gerbil model. World J Gastroenterol. 2009;15: 4907-4914.

13. Zhang LJ, Wang SY, Huo XH, et al. Anti-Helicobacter pylori therapy followed by celecoxib on progression of gastric precancerous lesions. World J Gastroenterol. 2009;15:2731-2738.

14. Grosch S, Maier TJ, Schiffmann S, Geisslinger G. Cyclooxygenase-2 (COX-2)-independent anticarcinogenic effects of selective COX-2 inhibitors. J Natl Cancer Inst. 2006;98(11):736-747.

15. Lee RC, Feinbaum RL, Ambros V. The C. elegans heterochronic gene lin-4 encodes small RNAs with antisense complementarity to lin- 14 . Cell. 1993;75:843-854.

16. Stefani G, Slack FJ. Small non-coding RNAs in animal development. Nat Rev Mol Cell Biol. 2008;9:219-230.

17. Ueda $\mathrm{T}$, Volinia $\mathrm{S}$, Okumura $\mathrm{H}$, et al. Relation between microRNA expression and progression and prognosis of gastric cancer: a microRNA expression analysis. Lancet Oncol. 2010;11:136-146.

18. Wu WK, Lee CW, Cho CH, et al. MicroRNA dysregulation in gastric cancer: a new player enters the game. Oncogene. 2010;29(43): 5761-5771.

19. Gomes LL, Moreira FC, Hamoy IG, et al. Identification of miRNAs expression profile in gastric cancer using Self-Organizing Maps (SOM). Bioinformation. 2014;10(5):246-250.

20. Shrestha S, Hsu SD, Huang WY, et al. A systematic review of microRNA expression profiling studies in human gastric cancer. Cancer Med. 2014;3(4):878-888.

21. Zhang Z, Li Z, Gao C, Chen P, et al. miR-21 plays a pivotal role in gastric cancer pathogenesis and progression. Lab Invest. 2008;88: 1358-1366.

22. Wang JL, Hu Y, Kong X, et al. Candidate microRNA biomarkers in human gastric cancer: a systematic review and validation study. PLoS One. 2013;8(9):e73683.

23. Zhang BG, Li JF, Yu BQ, et al. microRNA-21 promotes tumor proliferation and invasion in gastric cancer by targeting PTEN. Oncol Rep. 2012;27(4):1019-1026.

24. Zheng J, Wu C, Lin Z, et al. Curcumin up-regulates phosphatase and tensin homologue deleted on chromosome 10 through microRNAmediated control of DNA methylation - a novel mechanism suppressing liver fibrosis. FEBS J. 2014;281(1):88-103.
25. Ji X, Ji J, Shan F, Zhang Y, Chen Y, Lu X. Cancer-associated fibroblasts from NSCLC promote the radioresistance in lung cancer cell lines. Int J Clin Exp Med. 2015;8(5):7002-7008.

26. Sun WH, Su H, Zhang LJ, et al. Effects of gastrin receptor antagonist and cyclooxygenase-2 inhibitor on proliferation and apoptosis of gastric cancer cell. Zhonghua Yi Xue Za Zhi. 2006;86(4):250-254.

27. Connolly EC, Van Doorslaer K, Rogler LE, Rogler CE. Overexpression of miR-21 promotes an in vitro metastatic phenotype by targeting the tumor suppressor RHOB. Mol Cancer Res. 2010;8(5):691-700.

28. Shi GH, Ye DW, Yao XD, et al. Involvement of microRNA-21 in mediating chemo-resistance to docetaxel in androgen-independent prostate cancer PC3 cells. Acta Pharmacol Sin. 2010;31(7):867-873.

29. Xu LF, Wu ZP, Chen Y, Zhu QS, Hamidi S, Navab R. MicroRNA-21 (miR-21) regulates cellular proliferation, invasion, migration, and apoptosis by targeting PTEN, RECK and Bcl-2 in lung squamous carcinoma, Gejiu City, China. PLoS One. 2014;9(8):e103698.

30. Ren Y, Zhou X, Mei M, et al. MicroRNA-21 inhibitor sensitizes human glioblastoma cells U251 (PTEN-mutant) and LN229 (PTEN-wild type) to taxol. BMC Cancer. 2010;10:27.

31. Sha M, Ye J, Zhang LX, Luan ZY, Chen YB, Huang JX. Celastrol induces apoptosis of gastric cancer cells by miR-21 inhibiting PI3K Akt-NF-KB signaling pathway. Pharmacology. 2014;93(1-2):39-46.

32. Targosz A, Brzozowski T, Pierzchalski P, et al. Helicobacter pylori promotes apoptosis, activates cyclooxygenase (COX)-2 and inhibits heat shock protein HSP70 in gastric cancer epithelial cells. Inflamm Res. 2012;61(9):955-966.

33. Shi L, Chen J, Yang J, Pan T, Zhang S, Wang Z. MiR-21 protected human glioblastoma U87MG cells from chemotherapeutic drug temozolomide induced apoptosis by decreasing $\mathrm{Bax} / \mathrm{Bcl}-2$ ratio and caspase-3 activity. Brain Res. 2010;1352:255-264.

34. Salakou S, Kardamakis D, Tsamandas AC, et al. Increased Bax/Bcl-2 ratio up-regulates caspase-3 and increases apoptosis in the thymus of patients with myasthenia gravis. In Vivo. 2007;21(1):123-132.

35. Oki E, Baba H, Tokunaga E, et al. Akt phosphorylation associates with LOH of PTEN and leads to chemoresistance for gastric cancer. Int $J$ Cancer. 2005;117(3):376-380.

36. Osaki M, Oshimura M, Ito H. PI3K-Akt pathway: its functions and alterations in human cancer. Apoptosis. 2004;9(6):667-676.

37. Meng F, Henson R, Wehbe-Janek H, Ghoshal K, Jacob ST, Patel T. MicroRNA-21 regulates expression of the PTEN tumor suppressor gene in human hepatocellular cancer. Gastroenterology. 2007;133(2): $647-658$.
OncoTargets and Therapy

\section{Publish your work in this journal}

OncoTargets and Therapy is an international, peer-reviewed, open access journal focusing on the pathological basis of all cancers, potential targets for therapy and treatment protocols employed to improve the management of cancer patients. The journal also focuses on the impact of management programs and new therapeutic agents and protocols on

\section{Dovepress}

patient perspectives such as quality of life, adherence and satisfaction. The manuscript management system is completely online and includes a very quick and fair peer-review system, which is all easy to use. Visit http://www.dovepress.com/testimonials.php to read real quotes from published authors. 